Keio J. Med. 30: 193-204, 1981

\title{
THE EFFECT OF ELECTROCONVULSIVE THERAPY ON PLASMA CYCLIC-AMP, NON-ESTERIFIED FATTY ACID, TRYPTOPHAN AND TYROSINE IN DEPRESSION
}

\author{
YUTAKA SAWA \\ Department of Neuro-psychiatry, School of Medicine, Fujita-Gakuen \\ University, Toyoake, Aichi
}

(Received for publication November 13,1981 )

\begin{abstract}
Electroconvulsive therapy (ECT) was applied to nine endogenous depressed patients and the concentrations of cyclic-AMP (c-AMP), free (nonalbumin bound) tryptophan, total tryptophan, non-esterified fatty acid (NEFA) and tyrosine in the plasma were measured before and after the first single ECT. As for six patients that could be followed after a course of ECTs, the change of these components and clinical assessments with rating scales was also measured. The content of c-AMP was significantly increased at $1 \mathrm{~min}, 5 \mathrm{~min}, 10 \mathrm{~min}$ and $30 \mathrm{~min}$ after the first single ECT and returned to $121 \%$ on the average by $1 \mathrm{hr}$. As to the maximum content of free tryptophan of each patient from $1 \mathrm{~min}$ to $10 \mathrm{~min}$ after ECT, a significant increase was noted. Total tryptophan levels were significantly decreased at $5 \mathrm{~min}$ and $10 \mathrm{~min}$ after the first single ECT and gradually returned to the original level by $1 \mathrm{hr}$. The content of tyrosine was significantly increased just after the first single ECT and, conversely, a significant decrease was noticed at $1 \mathrm{hr}$ after ECT. NEFA was significantly decreased at $1 \mathrm{~min}$ and $5 \mathrm{~min}$ after the first single ECT. As for the six patients that could be followed concerning the changes of various components and clinical assessments, all six patients showed dramatic and significant improvement in both subjective and objective rating scales. Percent free tryptophan tended to increase significantly in these patients, but there was no significant change in c-AMP, total tryptophan, NEFA, and tyrosine values.
\end{abstract}

\section{INTRODUCTION}

Endogenous depression is a psychosis of unknown cause, and it is now mainly treated with antidepressants, especially tricyclic antidepressants. Electroconvulsive therapy (ECT) was created in 1938 (Cerletti and Bini) ${ }^{1}$, and had been used 
as the epoch-making treatment for depression and schizophrenia until the $1950 \mathrm{~s}$. But since the advent of the drug therapy, and because of erroneous uses and side effects such as temporary memory losses etc., ECT has been used less year by year. As it is often the quickest and surest way of relieving depression, however, it is still applied to severe depressed patients with suicidal motivation or stupor, or patients unresponsive to medication or with protracted depression. The mechanism of action of ECT, however, is not known though there have been many theories proposed.

The author applied ECT to patients diagnosed as endogenous depressive and measured the concentration of amino acids in the plasma after the first single ECT. The compounds measured included tyrosine, the precursor of catecholamines; tryptophan, the precursor of indoleamines; cyclic-AMP (c-AMP); and, non-esterified fatty acid (NEFA), which had the possibility to change the level of these amino acids. Furthermore, in a smaller group of patients, the change of clinical manifestations was assessed with rating scales and the changes of these various components in the plasma were determined before and after a course of ECTs.

\section{SUBJECTS AND METHODS}

\section{1) Subjects}

The subjects were nine patients, diagnosed as endogenous depressives following ICD $9(296.1,296.3)$ that were admitted to the neuro-psychiatric ward in Fujita-Gakuen University. Sex, age, type of depression, number of phase, medication, reason for indication of ECT, period before ECT since the onset of that phase and the beginning of medication, number of ECTs given and responses to ECT are presented in Table 1. Either the patients or their families consented to ECT and blood collection in all cases.

2) ECT administration

Each ECT was given at 10:00 am three times a week following the method of Yasukoti et al. ${ }^{2}$ with fasting for over $17 \mathrm{hr}$. and $500 \mathrm{mg}$ of amobarbital was administered intravenously at $30 \mathrm{~min}$ before ECT.

3) Blood collection

The blood was collected from the cubital vein 7 times, i.e. just before anesthesia-9:30, 9:55, just after ECT-approximately 10:01, 10:05, 10:10, $10: 30$, and 11:00 am. Each sample was divided into two tubes with EDTA-4Na for c-AMP assay and heparin for amino acids and NEFA. Immediately after blood collection, blood was centrifuged at $1000 \mathrm{~g}$ for $15 \mathrm{~min}$ at ice cold, and the plasma was kept frozen at $-20^{\circ} \mathrm{C}$ till measurement. 
4) Measurement of various components in the plasma

The content of c-AMP was measured using radioimmunoassay (YAMASA Cyclic AMP Assay Kit ${ }^{\circledR}$ ) (Honma et al. $^{3}$ ) ; NEFA was measured spectrophotometrically (NEFA Test WAKO ${ }^{\circledR}$ ) (Laurell et al. ${ }^{4}$ ). The contents of free (nonalbumin bound) tryptophan and total tryptophan were determined spectrofluorometrically (Denckla et al.5). The sample for free tryptophan was obtained by the centrifugation of $1 \mathrm{ml}$ plasma through Amicon Centriflo Membrane Cone CF50A at $1000 \mathrm{~g}$ for $30 \mathrm{~min}$ at $37^{\circ} \mathrm{C}$ (Knott et al. ${ }^{6}$ ). The content of tyrosine was spectrofluorometrically measured (Wong et al. ${ }^{7}$ ).

5) Clinical assessment

Clinical assessment was done with the self-rating depression scale (SDS) (Zung ${ }^{8}$ ) written by the patients themselves from 8:30 to 9:00 am and with Hamilton's ${ }^{9}$ and Bojanovsk'y's ${ }^{10}$ rating scales checked by the doctor while the patients were lying down from 9:00 to 9:30 am.

6) Medication

During the course of ECT 80 to $150 \mathrm{mg}$ of amitriptyline was used in eight patients (clomipramine in one patient) and a sleep inducer of benzodiazepine group was administered in two patients but their doses were scarecely changed.

Calculation of t-test and correlation coefficient was done using PDP 11 (Digital Equipment Corporation).

\section{RESULTS}

1) Changes of various components in the plasma before and after the first single ECT (Figure 1, 2, 3, 4, 5)

Figs. 1 to 5 show the changes of various components in the plasma before and after the first single ECT by converting the absolute value at 9:55 am into $100 \%$. The difference between the percent values of each time and that at 9:55 was tested (t-test; two-tailed).

Though the content of c-AMP in the plasma varied in each patient $(18.4$ to $35.5 \mathrm{pmole} / \mathrm{ml}$ ) at $9: 30 \mathrm{am}$ just before anesthesia, it became tolerably steady (16.1 to $27.5 \mathrm{pmole} / \mathrm{ml}$; mean $\doteq \mathrm{SD}=20.4 \pm 3.7 \mathrm{pmole} / \mathrm{ml}$ ) at $9.55 \mathrm{am}$. At $1 \mathrm{~min}$, $5 \mathrm{~min}, 10 \mathrm{~min}$, and $30 \mathrm{~min}$ after ECT, the percent change of c-AMP became significantly increased ( $\mathrm{p}<0.01, \mathrm{p}<0.05, \mathrm{p}<0.01, \mathrm{p}<0.05$ respectively), and returned to $121 \%$ on the average by $1 \mathrm{hr}$. This change is depicted in Fig. 1.

The content of free tryptophan in the plasma at 9:55 ranged between 1.81 and $5.89 \mathrm{nmole} / \mathrm{ml}$ (mean $\pm \mathrm{SD}=3.92 \pm 1.23 \mathrm{nmole} / \mathrm{ml}$ ). Concerning the percent values a significant increase was found just after ECT $(p<0.05)$ and more sig- 


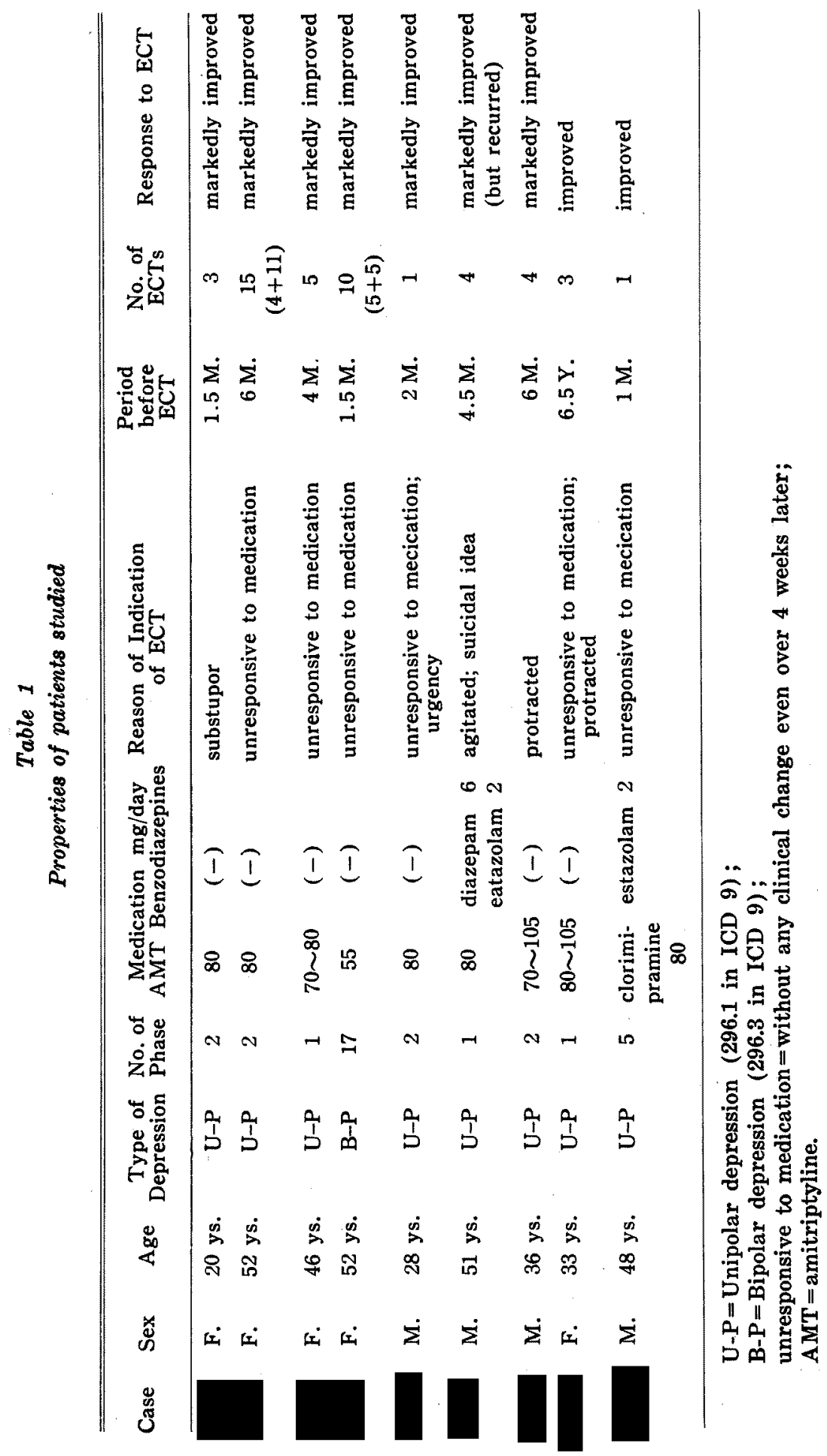




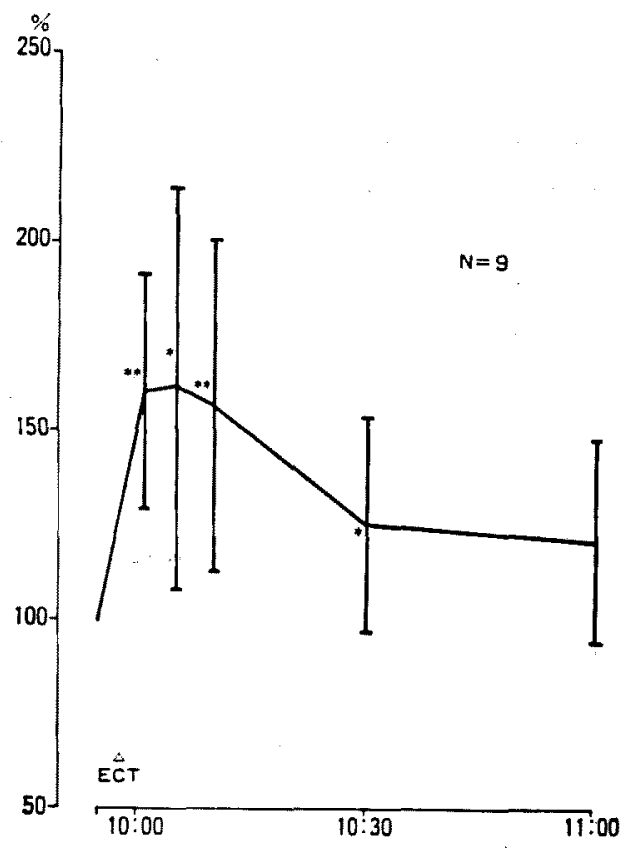

Fig. 1 The percent changes of the plasma level of c-AMP before and after the first single ECT

Different to values at $9: 55 * p<0.05$

${ }^{* *} \mathrm{p}<0.01$ Each point is the mean of nine patients and vertical lines indicate SD.

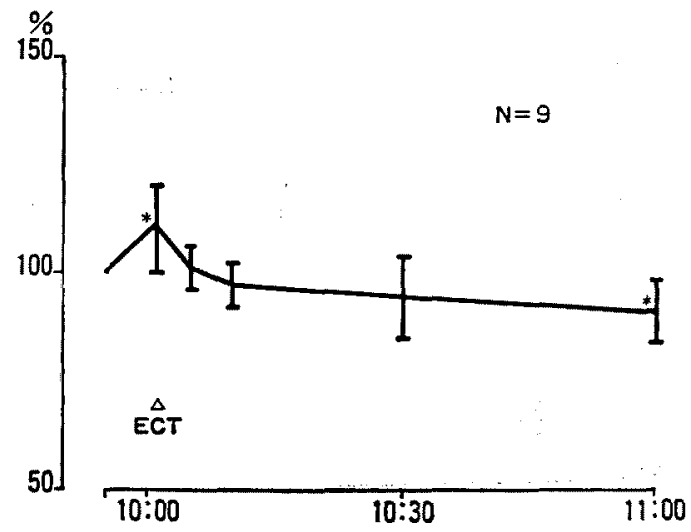

Fig. 2 The percent changes of the plasma level of free tryptophan before and after the first single ECT

Different to values at $9: 55 * \mathrm{p}<0.05$. 
nificant increase was found on the maximum value from $1 \mathrm{~min}$ to $10 \mathrm{~min}$ after ECT for each patient $(p<0.01)$. This change is presented in Fig. 2.

The content of total tryptophan in the plasma at 9:55 ranged between 45.2 and $124.5 \mathrm{nmole} / \mathrm{ml}$ (mean $\pm \mathrm{SD}=69.7 \pm 22.5 \mathrm{nmole} / \mathrm{ml}$ ). As for the change of percent value, a distinct significant decrease was found at $5 \mathrm{~min}$ and $10 \mathrm{~min}$ after ECT ( $p<0.01$ in both). This change gradually returned to the original level by $1 \mathrm{hr}$. This change is displayed in Fig. 3.

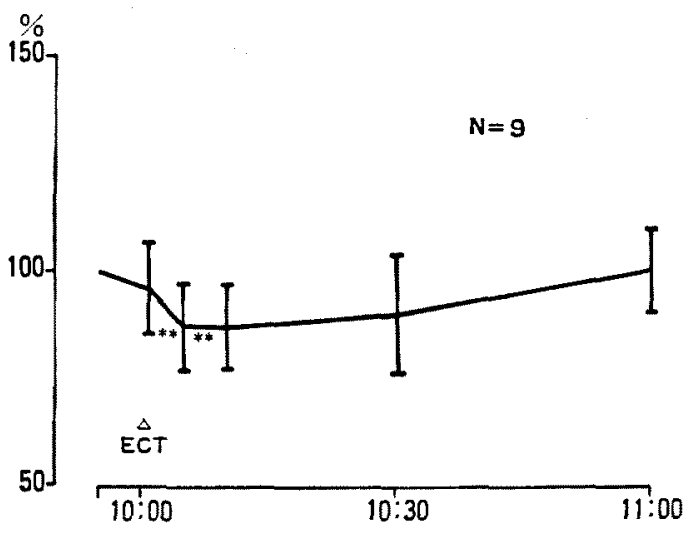

Fig. 3 The percent changes of the plasma level of total tryptophan before and after the first single ECT

Different to values at $9: 55 * * p<0.01$.

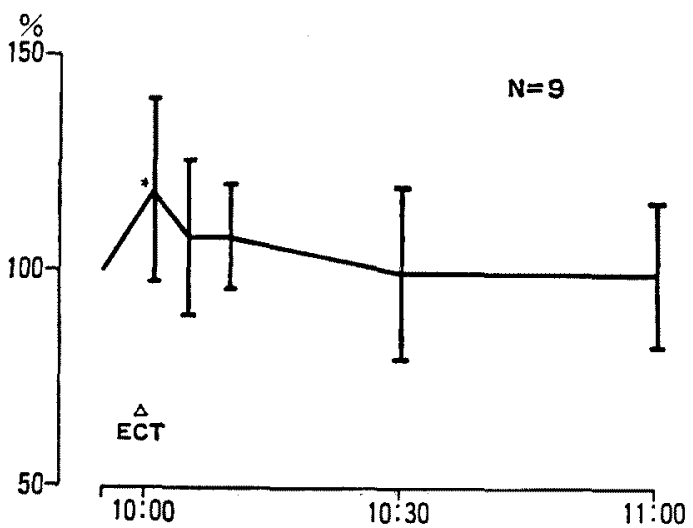

Fig. 4 The percent changes of the plasma level of tyrosine before and after the first single ECT

Different to values at $9: 55 * \mathrm{p}<0.05$. 
The content of tyrosine in the plasma at 9:55 ranged between 3.75 and 6.35 $\mu$ mole $/ \mathrm{dl}$ (mean $\pm \mathrm{SD}=\mathbf{5 . 0 6} \pm 0.8 \mu \mathrm{mole} / \mathrm{dl}$ ). Regarding the percent values, a significant increase was noticed at $1 \mathrm{~min}$ after ECT $(p<0.05)$, and it fell to the original level at $5 \mathrm{~min}$ after ECT and a significant decrease was found at $1 \mathrm{hr}$. after ECT $(p<0.05)$. This change is presented in Fig. 4.

The content of NEFA at 9:55 ranged between 0.83 and $1.071 \mathrm{mEq} / \mathrm{L}$ (mean $\pm \mathrm{SD}=0.450 \pm 0.245 \mathrm{mEq} / \mathrm{L}$ ). A significant decrease was noticed at $1 \mathrm{~min}$ and 5 min after ECT $(p<0.01)$ and at 10 min after ECT $(p<0.05)$ in the percent change. This change is displayed in Fig. 5.

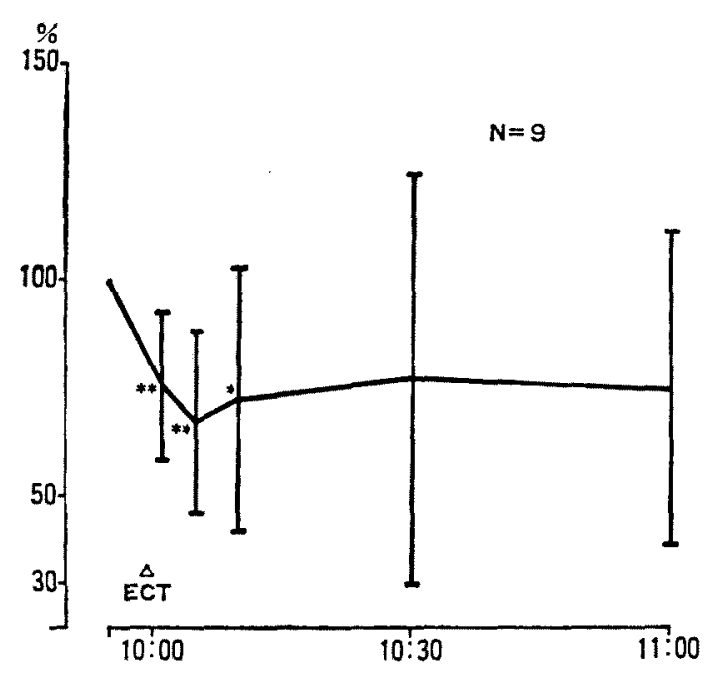

Fig. 5 The percent changes of the plasma level of NEFA before and after the first single ECT Different to values at $9: 55 * \mathrm{p}<0.05$ $* * p<0.01$.

A series of varied values of each component before and after ECT was paired for each patient and correlation coefficient was calculated. Significant correlation $(\mathrm{p}<0.05 ; \mathrm{r}>\mathbf{0 . 7 5 4})$ was noticed in two of nine patients between c-AMP and free tryptophan $(r=0.768,0.844$ respectively), in one of nine between free tryptophan and tyrosine $(r=0.780)$, and in one of nine between NEFA and tyrosine $(r=0.798)$; a significant reverse correlation was found in one of nine between $\mathrm{c}$-AMP and total tryptophan $(\mathrm{r}=-0.816)$. As a whole there was not any significant correlation, however any two of the various components were paired. In respect of the patient M.M., blood glucose and cortisol were also measured. Though corrclation coefficient was calculated including them, there was no sig- 
nificant correlation.

2) Changes of various components in the plasma and clinical manifestations before and after a course of ECTs (Fig. 6)

As to the six patients that could be followed on the changes of these various components and clinical assessments at 9:30 am before and after a course of ECTs, all six patients became dramatically and significantly improved in SDS, Hamilton's and Bojanovský's depression scales $(\mathrm{p}<0.01$ in all).

The level of c-AMP was increased in two patients, unchanged in one and tended to decrease in three. Free tryptophan became increased up to 137 to $168 \%$ in four patients, correlated with the clinical improvement. On the absolute values

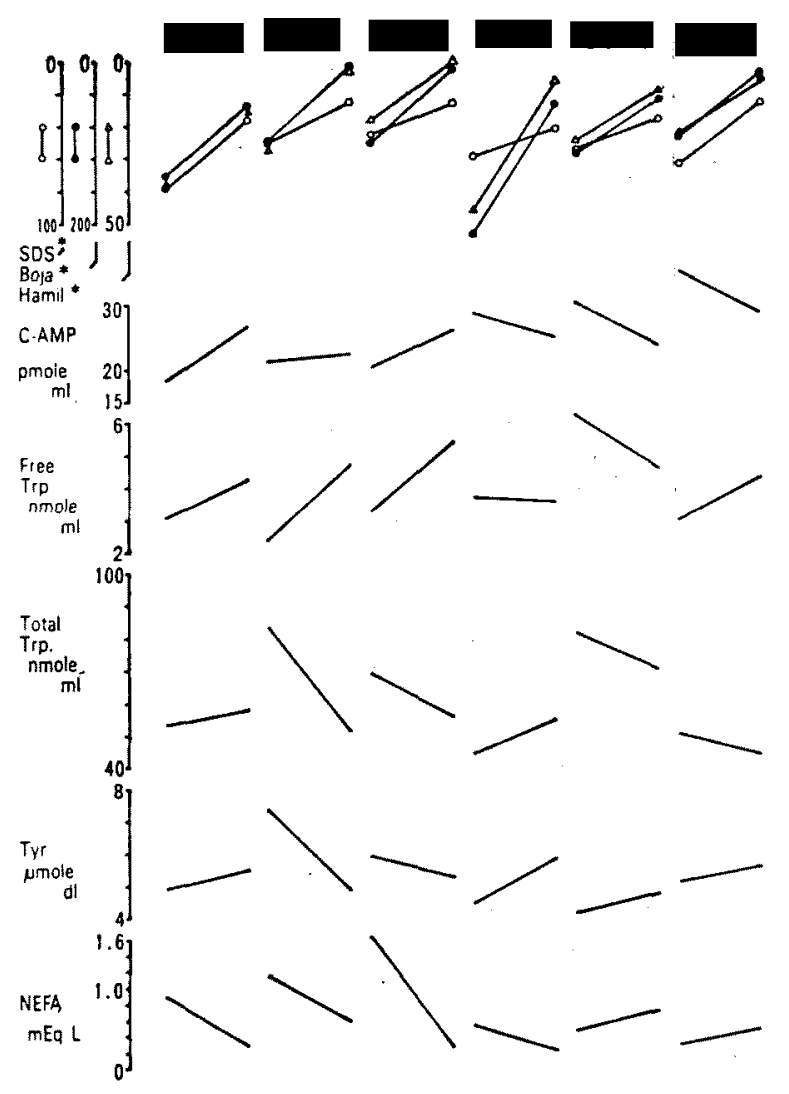

Fig. 6 The changes of the plasma level of c-AMP, free tryptophan, total tryptophan, tyrosine and clinical assessment before and after the course of ECTs Different to values before ECT $* \mathrm{p}<0.01$. 
statistical significance was not found but tendency to increase was noticed on the percent values $(p<0.1$, one-tailed). Total tryptophan tended to decrease in four and to increase in two. Tyrosine became increased in four and tended to decrease in two. No consistent tendency was found in the change of NEFA.

\section{DISCUSSION}

There are still many recent reports about the fact that ECT is an evidently useful and effective treatment (Avery et al. ${ }^{11}$; Freeman et al. ${ }^{12}$ ). Two recent reviews indicated that $\mathrm{ECT}$ is more effective than antidepressant drug therapy (Barton $^{13}$; Royal College of Psychiatrist ${ }^{14}$ ). In spite of numerous empirical studies indicating that ECT is really effective, the mechanism of action of ECT is not yet known.

In this study the contents of c-AMP, free tryptophan, total tryptophan, tyrosine and NEFA in the plasma were measured before and after the first single ECT in depressive patients, and clinical assessment was done with the measurement of these components before and after a course of ECTs.

Though the content of c-AMP was found to be increased significantly by $30 \mathrm{~min}$ after the first single ECT, there have been no reports of c-AMP content in the plasma following ECT. It was found that urinary excretion of c-AMP/ $24 \mathrm{hr}$. increased up to $310 \%$ on the day of ECT compared with before ECT (Hammadah et al. ${ }^{15}$ ). Brown et al. ${ }^{16}$ and Moyes et al. ${ }^{17}$, however, insisted that they could not find a significant increase of the urinary excretion of c-AMP. The origin of c-AMP in the urine is more obscure than that in the plasma. It was reported that $60 \%$ of urinary c-AMP was from glomerular filtration (Broadus et al. $\left.^{18}\right)$. The distinct and significant increase of c-AMP in the plasma during a period of $30 \mathrm{~min}$ after ECT could have been diluted in the urine for $24 \mathrm{hr}$. As it was suggested that c-AMP in the plasma might be a good indicator of the activity of the sympathetic nervous system (Honma et al. ${ }^{19}$ ), it was assumed that ECT might strongly activate the sympathetic nervous system. This appears to confirm the results of Weil-Malherbe ${ }^{20}$ and Havens et al.21, in which catecholamines in the blood were found to be increased just after ECT.

NEFA is generally thought to increase with the activation of hormone sensitive lipase due to the excitation of the sympathetic nervous system (Mallov et al. ${ }^{22}$ ). As NEFA was significantly decreased at $1 \mathrm{~min}$ and $5 \mathrm{~min}$ after ECT in this study, though the sympathetic nervous system might be strongly activated by ECT, it appears that re-esterification from NEFA was activated more through a certain mechanism with ECT, and overcame the increase of NEFA due to hydrolysis from lipoprotein.

It was reported that NEFA was increased up to $122 \%$ and free tryptophan up to $134 \%$ at $1 \mathrm{~min}$ after ECT (Stelmasiak et al. ${ }^{23}$ ). They suggested that ECT 
increased NEFA and so increased free tryptophan through a mechanism whereby free tryptophan was released from albumin by NEFA, which competed with free tryptophan in binding to albumin (Curzon et al..$^{24}$; Knott et al..$^{6}$ ). They reported further that the increase of free tryptophan in the plasma caused the increase of tryptophan and then the increase of 5-HT turnover in the brain (Curzon et al. ${ }^{25,26}$; Tagliamonte et al. ${ }^{27}$ ), and that ECT might improve depression through the same mechanism. As the free tryptophan level was definitely increased at 1 min after ECT, as Stelmasiak found, though NEFA was significantly decreased at $1 \mathrm{~min}$ and $5 \mathrm{~min}$ after ECT, this increase presumably is related to a mechanism other than theirs.

In this study the level of free tryptophan tended to increase in accordance with clinical improvement. This result was consistent with the report by Coppen et al. ${ }^{28}$ and might be important in the mechanism of action of ECT and the pathophysiology of depression in association with the indoleamine hypothesis of depression (Coppen ${ }^{29}$; Coppen et al. $^{30}$ ). The content of total tryptophan became significantly decreased at $5 \mathrm{~min}$ and $10 \mathrm{~min}$ after ECT. There have been no previous reports of this phenomenon, and the mechanism and the metabolic meaning of this result is not clear.

On the other hand, tyrosine, the precursor of catecholamines, was also significantly increased. There have been no reports of this phenomenon. It is important to investigate the mechanism of this phenomenon and its meaning in the effectiveness of ECT in association with catecholamine hypothesis of depression (Schildkraut ${ }^{31}$ ) and further study its relationship with indoleamine metabolism.

In this study intravenous anesthesia, amobarbital, was used. Although it was thought to influence the level of various components in the plasma, especially c-AMP, free tryptophan and NEFA. At 9:30 the levels of c-AMP, free tryptophan and NEFA were $24.9 \pm 5.3 \mathrm{pmole} / \mathrm{ml}, 3.82 \pm 1.46 \mathrm{nmole} / \mathrm{ml}$ and $0.569 \pm 0.287$ $\mathrm{mEq} / \mathrm{L}$ respectively and at 9:55 $20.4 \pm 3.7 \mathrm{pmole} / \mathrm{ml}, 3.92 \pm 1.23 \mathrm{nmole} / \mathrm{ml}$ and $0.450 \pm 0.245 \mathrm{mEq} / \mathrm{L}$ respectively. As the contents of c-AMP and NEFA were significantly decreased $(p<0.05)$ and SD of the levels of these components were decreased after anesthesia, these levels were thought to become stabilized in 25 min after anesthesia. Furthermore, in the cases A.K., M.O. and Y.T. the contents of c-AMP, free tryptophan and NEFA during amobarbital anesthesia without ECT were measured for the same period of time as ECT. There was no consistent and significant change of the contents of these components.

There remain several questions in this study: 1) Are these changes specific in depression or non-specific change following ECT? 2) What is the indispensable change to improve depression? 3) What about the improved patients who did not show significant change? 4) How much does the real convulsion and the temporary hypoxia during ECT influence these results? 5) How do the temporary 
changes sustain the clinical improvement even after a course of ECTs? 6) Were these subjects in this study only a subgroup of depressive patients unresponsive to medication? As the level of various components in the plasma is related to the sum of synthesis, degradation, influx and efflux, how these changes in the plasma influence the metabolism in the brain and behavior must be investigated further in animal experiments, now in progress.

\section{ACKNOWLEDGEMENTS}

The author is very grateful to Prof. Hideo Hosaki, Chairman of the Department of Neuro-psychiatry in Keio University, for his reviewing this manuscript in detail, to Prof. Tsuneyuki Nakazawa, Chairman of the Department of Neuro-psychiatry in Fujita-Gakuen University, for the valuable comments on this manuscript, to Associate Prof. Hitoshi Itoh, the Research Director in the Department of Neuro-psychiatry in Keio University, for his comments and encouragement, to Prof. Motohiko Otani, Chairman of the Department of Hygiene in Fujita-Gakuen University, for statistical analysis, and to Miss Mayumi Ikeya, for her expert and elaborate technical assistance.

This study was supported in part by Grant-in-Aid for Encouragement of Young Scientist No. 377392 from the Ministry of Education, Science and Culture.

A part of this paper was read at the 2nd World Congress of Biological Psychiatry, in September 1978, in Barcelona.

Reprint requests should be directed to Dr. Yutaka Sawa, Department of Neuro-psychiatry, School of Medicine, Fujita-Gakuen University, Toyoake City, Aichi Prefecture 470-11.

\section{REFERENCES}

1. Cerletti, U. and Bini, L.: L'Electroshock. Archivivo Generale di Neurologia, Psichiatria e Psicoanalisi 19: 266-268, 1938

2. Yasukoti, G. und Mukasa, H.: Electroshocktherapie der Schizophrenie. Fukuoka Acta Medica. 32: 1437-1440 (abstract in Germany 81-83), 1939

3. Honma, M., Satoh, T., Takezawa, J. et al.: An ultrasensitive method for the simultaneous determination of cyclic-AMP and cyclic-GMP in small-volume samples from blood and tissue. Biochemical Medicine 18: 257-273, 1977

4. Laurell, S. and Tibbling, G.: Colorimetric micro-determination of free fatty acids in plasma. Clinica. Chimca. Acta. 16: 57-62, 1966

5. Denckla, W.D. and Dewey, H.K.: The determination of tryptophan in plasma, liver, and urine. Journal of Laboratory and Clinical Medicine 69: 160-169, 1967

6. Knott, P. J. and Curzon, G.: Free tryptophan in plasma and brain tryptophan metabolism. Nature 239: 452-453, 1972

7. Wong, P.W. K., O'Flynn, M. E. and Inoue, T.: Micromethods for measuring phenylalanine and tyrosine in serum. Clinical Chemistry 10: 1098-1104, 1964

8. Zung, W. W. K.: A self-rating depression scale, Archives of General Psychiatry 12: 63-70, 1965

9. Hamilton, M.: A rating scale for depression. Journal of Neurology, Neurosurgery and Psychiatry 23: 56-62, 1960

10. Bojanovsky, J. and Chloupková, K.: Bewertungsskala der Depressionszustände. Psychiatria et Neurologia, Basel. 151: 54-61, 1966

11. Avery, D. and Winokur, G.: The efficacy of electroconvulsive therapy and anti- 
depressants in depression. Biological Psychiatry 12: 507-523, 1977

12. Freeman, C. P. L., Basson, J. V. and Crighton, A.: Double-blind controlled trial of electroconvulsive therapy (E.C.T.) and simulated E.C.T. in depressive illness. Lancet I: 738-740, 1978

13. Barton, J. L.: ECT in depression: The evidence of controlled studies. Biological Psychiatry 12: 687-695, 1977

14. Royal College of Psychiatrists: The royal college of Psychiatrists' memorandom on the use of electroconvulsive therapy. British Journal of Psychiatry 131: 261272,1977

15. Hamadah, K., Holmes, H., Barber, G. B. et al.: Effect of electric convulsion therapy on urinary excretion of $3^{\prime}, 5^{\prime}$ cyclic adenosine monophosphate. British Medical Journal 19: 439-441, 1972

16. Brown, S. J. G., Albano, J.D. M., Hullin, R. P. et al.: Urinary excretion of cyclic AMP and manic-depressive psychosis. British Journal of Psychiatry 120: 405408, 1972

17. Moyes, R. B. and Moyes, I. C. A.: Urinary adenosine $3^{\prime} 5^{\prime}$-cyclic monophosphate: Effects of electroconvulsive therapy. British Journal of Psychiatry 129: 173-177, 1976

18. Broadus, A. E., Kaminsky, N. I., Hardman, J. G. et al.: Kinetic parameters and renal clearances of plasma cyclic AMP and cyclic GMP in man. Clinical Research 18: 73,1970

19. Honma, M. and Kunitada, S.: Plasma levels of cyclic AMP and cyclic GMP as reliable indices for adrenergic and cholinergic functions in rats. Abstracts: The 3rd cyclic nucleotide conference. 3: 13-17, (abstract in English 139), 1978

20. Weil-Malherbe, H.: The effect of ECT on plasma adrenaline and noradrenaline. Journal of Mental Science 101: 156-162, 1955

21. Havens, L. L., Zilleli, M. S., Di Mascio, A. et al.: Changes in catechol amine response to successive electric convulsive treatments. Journal of Mental Science 105: 821-829, 1959

22. Mallov, S. and Witt, P. N.: Effects of stress and tranquilization on plasma free fatty acid levels in the rat. Journal of Pharmacology and Experimental Therapeutics 132: 126-130, 1961

23. Stelmasiak, Z. and Curzon, G.: Effects of electroconvulsive therapy on plasma unesterified fatty acid and free tryptophan concentration in man. Journal of Neurochemistry 22: 603-604, 1974

24. Curzon, G., Friedel, J. and Knott, P. J.: The effect of fatty acids on the binding of tryptophan to plasma protein. Nature 242: 198-200, 1973

25. Curzon, G. and Knott, P.J.: Drugs influencing plasma and brain tryptophan. British Journal of Pharmacology and Chemotherapy 48: 352 p.-353 p., 1973

26. Curzon, G., Kantamaneni, B. D., Winch, J. et al.: Plasma and brain tryptophan changes in experimental acute hepatic failure. Journal of Neurochemistry 21: 137-145, 1973

27. Tagliamonte, A., Biggio, G., Vargiu, L. et al.: Free tryptophan in serum controls brain tryptophan level and serotonin synthesis. Life Science 12 (Part 2) : 277-287, 1973

28. Coppen, A., Eccleston, E. G. and Peet, M.: Total and free tryptophan concentration in the plasma of depressive patients. Lancet II: 60-63, 1973

29. Coppen, A.: The biochemistry of affective disorders. British Journal of Psychiatry 113: $1237-1264,1967$

30. Coppen, A., Prange, Jr., A.J., Whybrow, P. C. et al.: Abnormalities of indoleamines in affective disorders. Archives of General Psychiatry 26: 474-478, 1972

31. Schildkraut, J. J.: The catecholamine hypothesis of affective disorders (A review of supporting evidence). American Journal of Psychiatry 122: 509-522, 1965 